\title{
Effect of the Cutting Conditions on Surface Roughness during 5-Axis Grinding of Maraging Steel MS1
}

\author{
Jindřich Farský1, Miroslav Zetek ${ }^{1}$, Tomáš Bakša ${ }^{1}$, Dana Kubátová ${ }^{1}$, Yuan Hu² \\ ${ }^{1}$ Regional Technological Institute, University of West Bohemia - Faculty of Mechanical Engineering, Univerzitní \\ 8, Pilsen 306 14, Czech Republic. E-mail: farskyj@rti.zcu.cz, mzetek@rti.zcu.cz, baksa@rti.zcu.cz, kuba- \\ tova@rti.zcu.cz \\ 2The University of Toledo - College of Engineering - Mechanical Industrial Manufacturing Engineering, $2801 \mathrm{~W}$. \\ Ban-croft street, Toledo, Ohio 43606. United States. E-mail: Yuan.hu@rockets.utoledo.edu
}

This work deals with the effect of the cutting conditions and the spindle tilt on the surface roughness when grinding complex shaped surfaces of Maraging steel MS1 on an ANCA MX7 5-axis tool grinding machine. It is necessary to grind complex shaped surfaces where high surface quality is important and requested. For this experiment was selected a component with a complex shaped surface which was printed on the 3D printer machine from maraging steel MS1. Since grinding of complex surfaces is being investigated, it is necessary to use CAM software for creating an NC program. The aim of this work is to study the effects of the cutting conditions on the grinding of a complex shaped surface in relation to the resulting surface roughness. To do this, it was necessary to design an experiment with the appropriate grinding technology, create a clamp, and create NC data in NX CAM software for grinding the complex shape surfaces on the part.

Keywords: General shape surface, Grinding, 5-axis grinder, Surface roughness, NX, CAM

\section{Introduction}

In many industries it is necessary to achieve high quality surfaces for components with complex shape surfaces. Therefore the surface quality of these components is an issue which is very frequently dealt with. In order to achieve very high surface quality it is necessary to use grinding as a finishing operation. To achieve high-quality surfaces even for complex shaped surfaces it is necessary to use a multi-axis grinding machine, because the complexity and required surface quality of some shaped components do not allow the use of conventional grinding machines or other production technologies. One of these products can be medical implants in which is very necessary to achieve a very good surface structure. Therefore was used the 5 -axis grinder machine with a special postprocessor for creating technology for grinding this component in which the shape was the same as the medical knee implant. From the research of this topic is evident there is a lot of problematics about surface quality. For example microcracks from grinding which can lead to deteriorating friction, make bigger cracks and so on. Also, it is necessary to take into account the used material doesn't use for medical purposes. This work has only used the shape of knee implant as a good representative of a complexity shaped surface.[1], [2]
Surface roughness is one of the most significant surface quality indicators. Surface roughness is most affected by the choice of the cutting conditions for grinding [3], [4]. When the correct combination of cutting conditions is selected, it is possible to achieve the required quality of these surfaces. Of course, it also depends on the material which is ground and on the grinding wheel which is used for grinding.

This paper therefore deals with the influence of cutting conditions and spindle tilt on the surface roughness, as the correct choice of the cutting conditions has a high impact on the surface roughness, which is confirmed in other articles [5], [6]. [7], [8]. The cutting speed is the cutting condition which has the greatest influence on the surface roughness. The influence of cutting speed on the process parameters and output is shown in Fig. 1.

The cutting speed also determines to which grinding group it belongs. There are 3 basic groups for grinding, which are shown in Tab. 1. Two cutting speeds were selected for this experiment, one from the grinding group with standard cutting speeds and the second from the high-speed grinding group. Values for the experiment are selected only up to $50 \mathrm{~m} . \mathrm{s}^{-1}$ because the grinding machine used for this experiment does not allow higher cutting speeds due to the maximum spindle speed being limited to $10000 \mathrm{rpm}$. [9] 

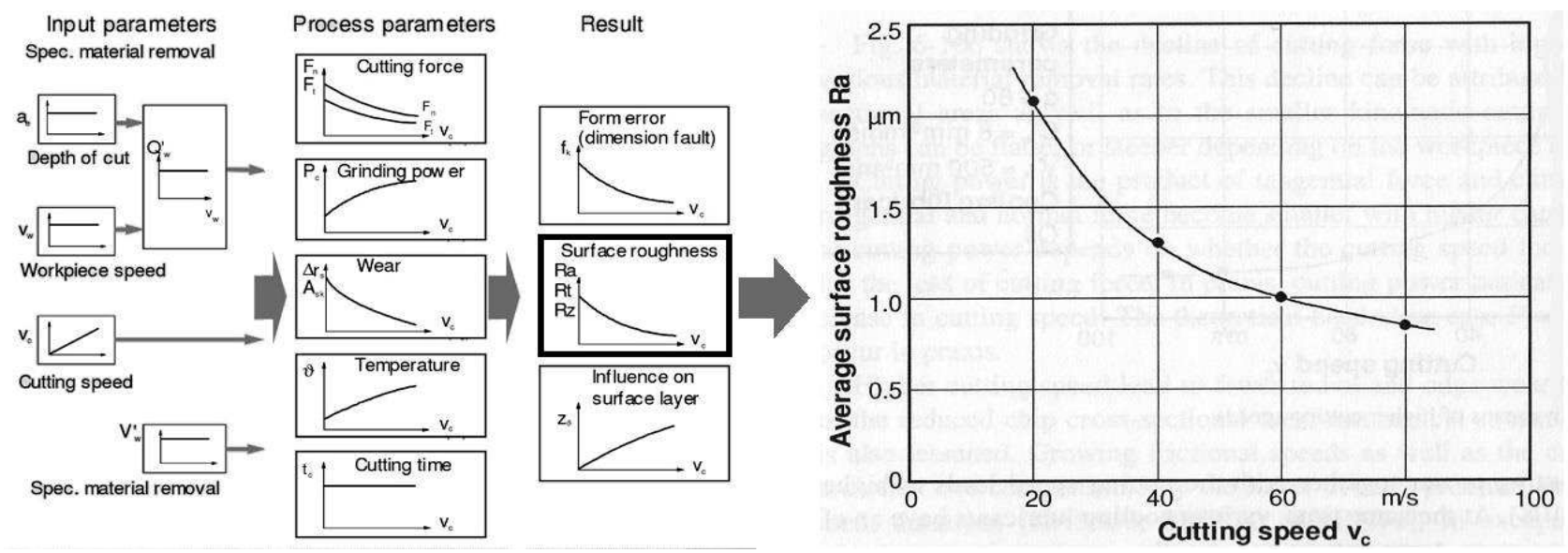

Fig. 1 The influence of cutting speed on process parameters and output [3]

Tab. 1 The basic groups of grinding speeds

\section{Name of groups}

Grinding with standard cutting
speeds

High Speed grinding

Ultra-high speed grinding

\section{Material properties}

Maraging steel MS1 is pre-alloyed ultra-high strength steel in fine powder form manufactured by EOS. This material is ideal for many tooling applications such as tools for pressing, punching, extrusion, pressure casting of aluminium alloys, and also for high performance industrial and engineering parts in the airplane industry, rocket technology and motor racing

\section{Cutting speed $\left[\mathrm{m} . \mathrm{s}^{-1}\right]$}

$$
\begin{gathered}
0-35 \\
35-100 \\
>100
\end{gathered}
$$

Maximum spindle speed [rpm] (diameter of grinding wheel is $100 \mathrm{~mm}$ )

$$
\begin{gathered}
0-6685 \\
6685-19100 \\
>19100
\end{gathered}
$$

$\begin{array}{ccccc}\begin{array}{c}\text { Tab. 2 Comparison of properties of maraging steel in powder form and standard form [10], [11] } \\ \text { Form of material } \\ \text { Tensile } \mathbf{R}_{\mathbf{m}}\end{array} & \begin{array}{c}\text { Yield } \mathbf{R}_{\mathbf{p} 0.2} \\ \text { [MPA] }\end{array} & \begin{array}{c}\text { Charpy Im- } \\ \text { pact [J] }\end{array} & \begin{array}{c}\text { Rockwell Hardness } \\ \text { [HPA] }\end{array} \\ \begin{array}{lccc}\text { [MPA] } \\ \text { Powder MS1 }\end{array} & 1100 \pm 100 & 1000 \pm 100 & 45 \pm 10 & 33-37 \\ \text { Standard } & 777(\geq) & 816(\geq) & 41 & 23\end{array}$

\section{Introducing the experiment}

This experiment deals with the surface roughness of a complex shape surface after grinding and the influence of the cutting parameters and tilt of the spindle on the surface roughness. Complex shape surfaces are usually difficult to define and also difficult to machine for these reasons, and it is expected that the influence of the cutting parameters on the surface roughness may be different than expected. The part which was selected as an example of a complex shape surface is shown on Fig. 2. It is not used for medical purposes because the semi-finished product (Fig. 3) for this experiment is made of MS1 maraging steel on a $3 \mathrm{D}$ printing machine. applications. This material contains Nickel, Cobalt, Molybdenum and Titanium. Therefore it is designated by German notation as X3NiCoMoTi 18-9-5 and according to European designation as 1.2709. Maraging steel in powder form has better properties than standard maraging steel. For example, the hardness of this MS1 steel is 33 - 37 HRC in the normal state and 50 54 HRC after age hardening. The properties of these materials are compared in Tab. 2. [10], [11] 


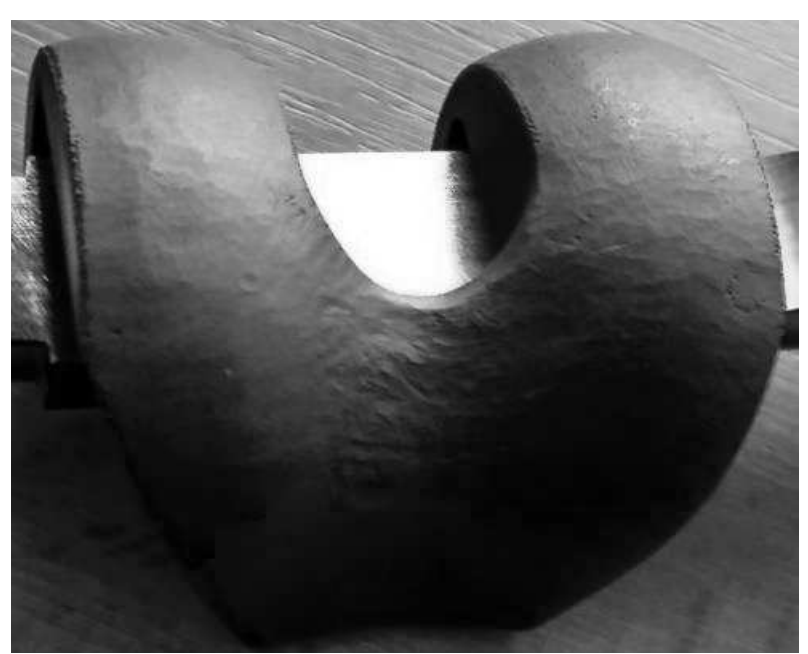

Fig. 3 Semi-finished component

The composition of the grinding wheel has a considerable influence on the final surface quality. Therefore it was necessary to select the most appropriate grinding wheel for this experiment. A grinding wheel which is marked as 1FF1 B64C75B54 was selected for grinding this component. The shape of this wheel is radius due to the shape of the component, and the basic dimensions are 100x6xR3 (diameter $\mathrm{x}$ width $\mathrm{x}$ radius). The grinding wheel's abrasive grains are Cubic Boron Nitride with grain size $64 \mu \mathrm{m}$ and with a resin binder. The maximum cutting speed for this grinding wheel is 63 m.s.- The grinding wheel was clamped on the clamping mandrel, with a mechanism for supplying the process fluid (Fig. 4). [4]

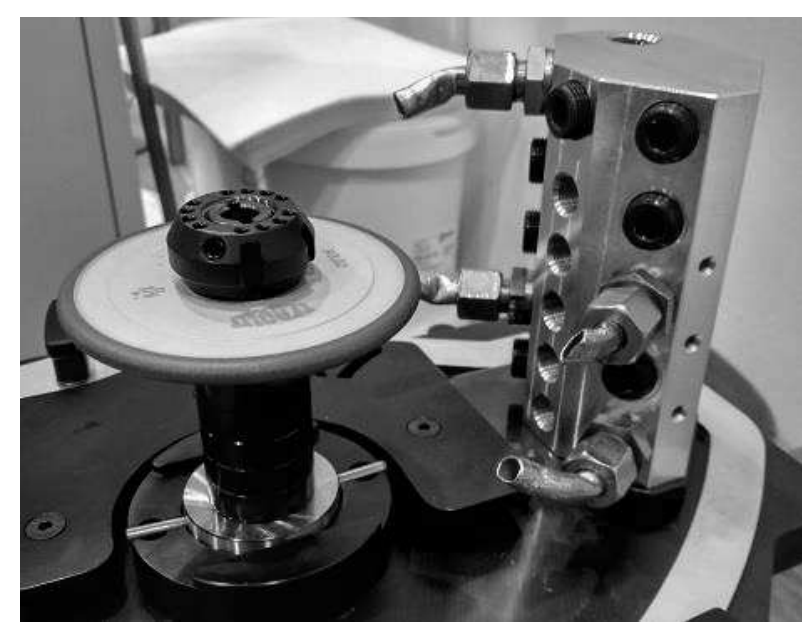

Fig. 4 The grinding wheel with mechanism for process fluid

The variables for this experiment are selected on the basis of the literature search mentioned above. Radial feed " $a_{e}$ " is depth of cut, cutting speed (grinding speed) " $v_{c}$ ", feed rate " $v_{f}$ " and tilting the spindle " $C$ ". In this experiment axial feed was set up as maximum scallop height "sc" because we are using NX software for creating $\mathrm{NC}$ data for grinding. The values of input parameters for this experiments are shown in Tab. 3. The value of the cutting speed is limited by the maximum spindle speed, which is $10000 \mathrm{rpm}$. Tilting the spindle was done during the experiment so that the first half of the component was ground without tilting the spindle and the second half of the component was ground with the spindle tilted by $30^{\circ}$ degrees.

Tab. 3 Experiment values

$\begin{array}{lccccc} & \mathbf{s c}[\mathbf{m m}] & \mathbf{a}_{\mathrm{e}}[\mathbf{m m}] & \mathbf{v}_{\mathbf{c}}\left[\mathbf{m} . \mathbf{s}^{-1}\right] & \mathbf{v}_{\mathbf{f}}\left[\mathbf{m m . \mathbf { m i n } ^ { - 1 } ]}\right. & \mathbf{C}\left[{ }^{\mathbf{0}}\right] \\ \text { EXP01 } & 0.005 & 0.05 & 30 & 150 & 0 ; 30 \\ \text { EXP02 } & 0.005 & 0.05 & 40 & 150 & 0 ; 30 \\ \text { EXP03 } & 0.005 & 0.05 & 30 & 200 & 0 ; 30 \\ \text { EXP04 } & 0.005 & 0.05 & 40 & 200 & 0 ; 30 \\ \text { EXP05 } & 0.001 & 0.05 & 30 & 150 & 0 ; 30 \\ \text { EXP06 } & 0.001 & 0.05 & 40 & 150 & 0 ; 30 \\ \text { EXP07 } & 0.001 & 0.05 & 30 & 200 & 0 ; 30 \\ \text { EXP08 } & 0.001 & 0.05 & 40 & 200 & 0 ; 30\end{array}$

\section{Experiment and results}

This experiment was carried out on an ANCA MX7 tool-grinding machine using a radius grinding wheel with the marking $1 \mathrm{FF} 1$. It was necessary to create NC data for this experiment in NX CAM software. After each experiment a Hommel Etamic T8000 highprecision contour/surface roughness measuring machine was used to measure the roughness of the surfaces (Fig. 5). Four cross sections were selected on the component (Fig. 6) and on each of them the surface roughness was measured several times in 4 different places on the curve.

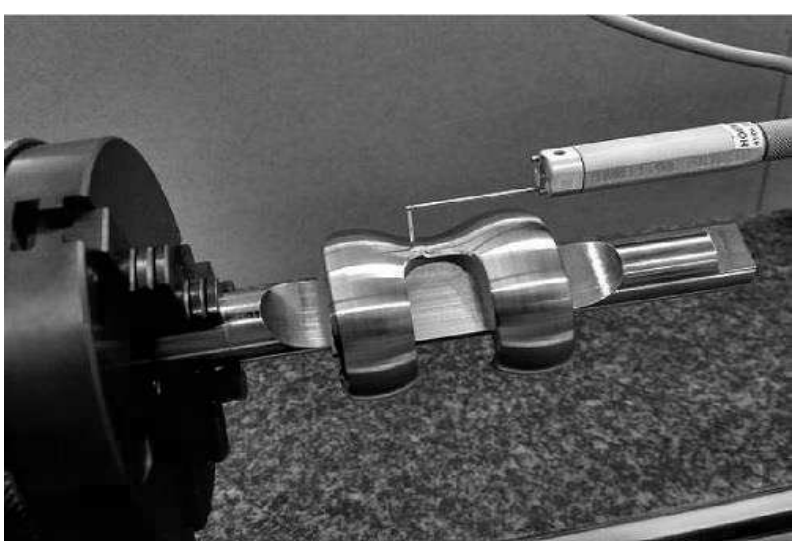

Fig. 5 Measurement of roughness using the Hommel Etamic T8000 
The measured values of roughness in parameters $\mathrm{Ra}$ for each experiment was recorded on the graph. The position of measured on the parts is taken into account in these graphs. The dependence and change of the surface roughness in relation to the cutting parameters and tilt of the spindle is apparent from the graph.

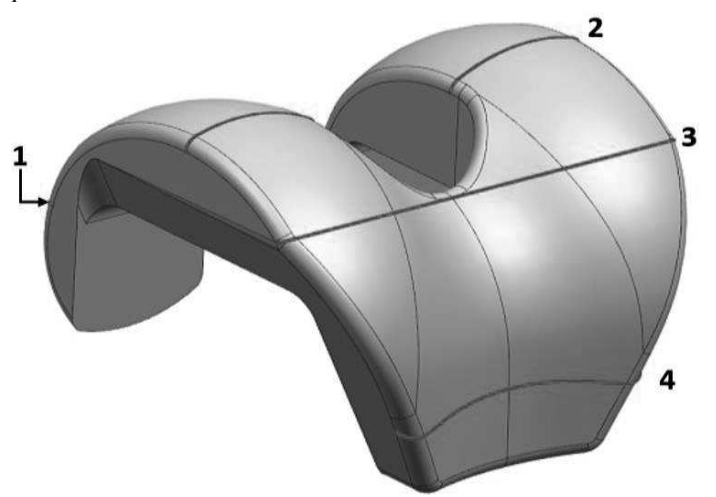

Fig. 6 View from one side of the sections cut for measuring roughness

\subsection{Dependence of the cutting parameters on the sur- face roughness}

For better comparison are results from the experiment divided into two graphs. The first comparison of the surface roughness in relation to the cutting parameters are the experiments which have parameter sc $=$ $0.001 \mathrm{~mm}$. These are marked EXP05 - EXP08. These values of roughness are shown in Graph 1 . The value of $\mathrm{Ra}$ is smaller for cutting speed $\mathrm{v}_{\mathrm{c}}=40 \mathrm{~m} / \mathrm{s}$ than for cutting speed $v_{c}=30 \mathrm{~m} / \mathrm{s}$. This change of surface roughness was expected, as the quality of the surface is improved with increasing cutting speed. Conversely, at a value of sc $=0.005 \mathrm{~mm}$ the surface roughness is bigger for the value of cutting speed $\mathrm{v}_{\mathrm{c}}=30 \mathrm{~m} / \mathrm{s}$ than for the value of $\mathrm{v}_{\mathrm{c}}=40 \mathrm{~m} / \mathrm{s}$ and these are the experiments marked EXP01 - EXP04. This change of roughness is shown in Graph 2 and it may be caused by the grinding wheel paths being too widely spaced out.

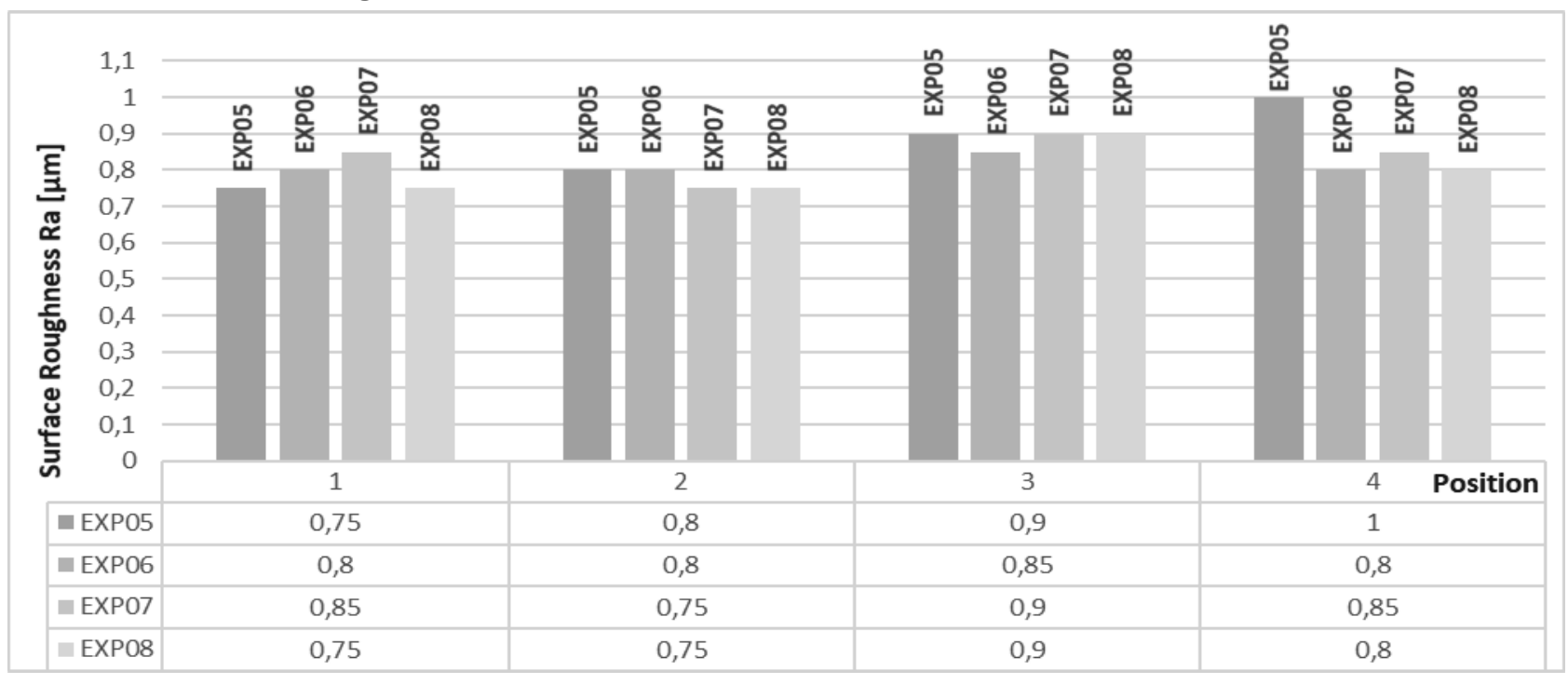

Graph 1 Average value of $\mathrm{Ra}$ at sc $=0.001 \mathrm{~mm}$



Graph 2 Average value of $R a$ at sc $=0.005 \mathrm{~mm}$ 
On these graphs (Graph 1, Graph 2) can also be seen the dependence of the surface roughness on the values of the feed rates. In both cases the course of this is the same and the surface roughness decrease as the feed rate increases. The graphs also show the difference of the values of surface roughness during grinding with the maximum scallop height set as 0.001 $\mathrm{mm}$ and with the value of maximum scallop height as $0.005 \mathrm{~mm}$. The value of surface roughness for the smaller "sc" is almost two times better than for the larger "sc". The measured values of roughness are also influenced by the position of measured on the surface of the part. As you can see on the graphs the first and second measured position has better results. The size of differences is lower for grinding with the value of scallop height of $0.001 \mathrm{~mm}$. The differences are not too hight for this value of scallop height. However, for the value of the scallop height of $0.005 \mathrm{~mm}$ are larger.

\subsection{Relation of tilting the spindle to the surface rou- ghness}

Another variable which influences surface roughness is the tilt of the spindle. As can be seen in Graph 3 , the values of surface roughness $\mathrm{Ra}$ are better without tilting the spindle than with tilting the spindle by $30^{\circ}$ degrees. This difference is more noticeable for values on the left side of this graph, because the paths of the grinding wheel are more distant from each other. The difference between the surface roughness for experiments EPX01 - EXP04 is approximately $0.34 \mu \mathrm{m}$ and for experiments EXP05 - EXP08 it is approximately $0.031 \mu \mathrm{m}$. Therefore it can be judged that if the value of maximum scallop height (axial feed rate) declines, the influence of tilting the spindle on the final state of surface roughness is smaller.

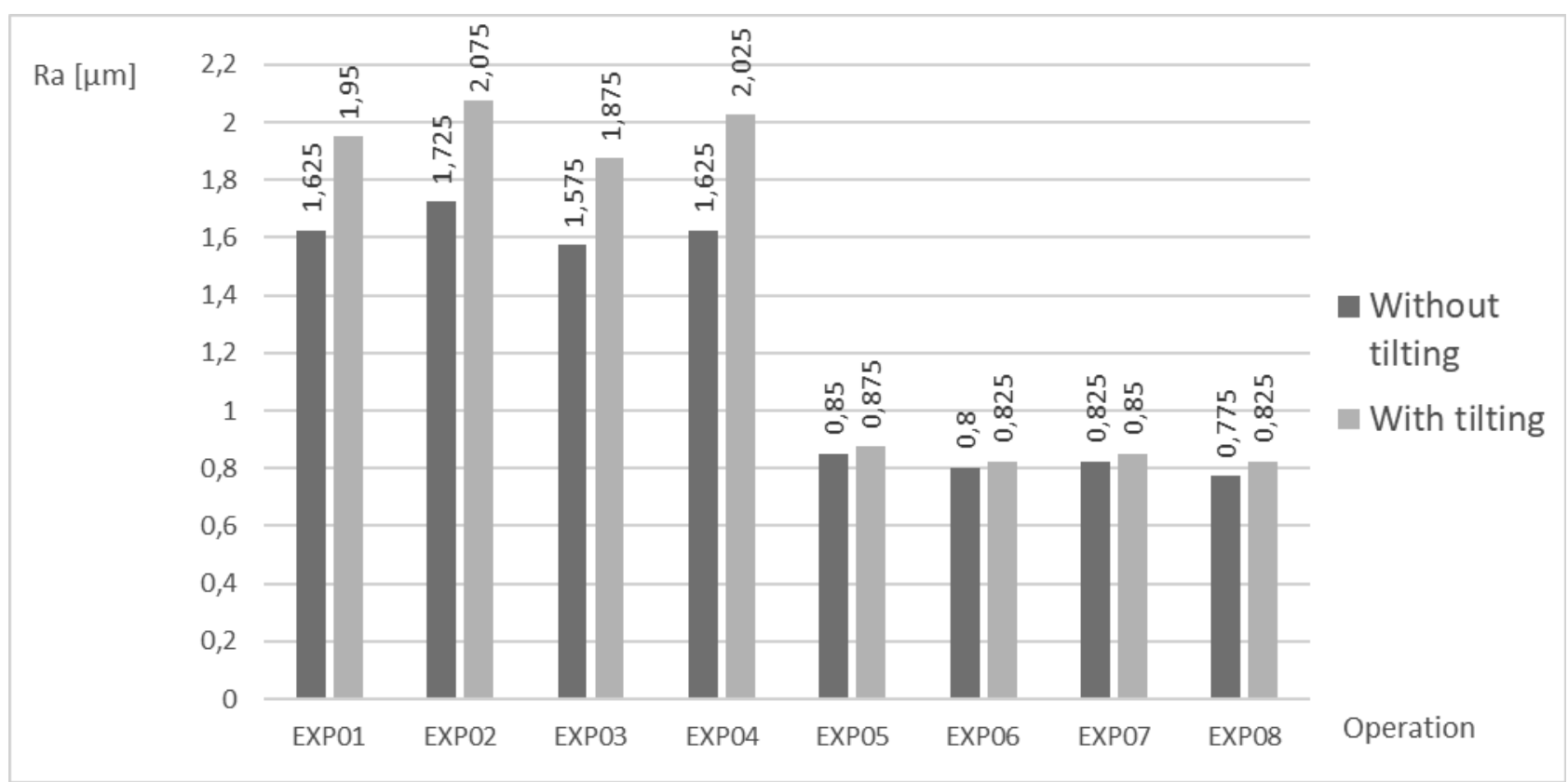

Graph 3 Influence of tilting the spindle on surface roughness $\mathrm{R} a$

\section{Conclusion}

This work presents results obtained from investigating the influence of the cutting parameters and tilt of the spindle on surface roughness. The experiments were conducted on an example of a complex shape surface. The semi-finished part was made of maraging steel MS1 on a 3D printing machine. The experiments obtained the values of the surface roughness achieved using different cutting parameters and tilts of the spindle. From the results it is obvious that the size of the maximum scallop height (axial feed rate) has the greatest impact on the roughness of the surface when changing the cutting speed and tilt of the spindle. If we neglect the effect of the axial feed, then the cutting speed has the greatest influence on the surface roughness. The next influencing factor is the feed rate and the last is the spindle tilt (Graph 4). Surface roughness very much depends on the axial feed rate, and if the value of the axial feed rate is smaller, then the influence of the spindle tilt on the surface roughness is smaller, as shown in Graph 3.

It may be stated that the results from this experiment are valid for grinding a part made of MS1 maraging steel using a radius grinding wheel $1 \mathrm{FF} 1$. When grinding a different type of material the results may be different for the surface roughness, but the change of surface roughness may be very similar, as evidenced by the similarity of our results to work by other researchers. 




Graph 4 The percentage size of influence of cutting parameters and spindle tilt on the surface roughness

The grinding of complex shape surfaces is a very large topic and these results serve to further the research and development of multi-axis grinding technologies for grinding complex shape surfaces.

\section{Acknowledgement}

This paper was supported by the Internal Grant Agency of the University of West Bohemia, project No. SGS-2019-008. Research and Development for Innovation in the Field of Manufacturing Technology - Machining Technology III.

\section{References}

[1] SUN, D. W. et al., 'Finite Element Analysis of Machining Damage in Single-Grit Grinding of Ceramic Knee Implants', Procedia Manuf., vol. 1, pp. 644-654, 2015. ISSN: 23519789

[2] TURGER, A., KOHLER J., DENKENA B., CORREA T. A., BECHER C. and HURSCHLER C., 'Manufacturing conditioned roughness and wear of biomedical oxide ceramics for all-ceramic knee implants', Biomed. Eng. Online, vol. 12, no. 1, 2013. ISSN: 1475925X

[3] KLOCKE, F. (2009). In Manufacturing Processes 2: Grinding, Honing, Lapping. Springer Science \& Business Media.

[4] DAVIM, J. P. (2011). Modern Machining Technology: A Practical Guide. Elsevier.

[5] NOVAK, M. (2012) 'Surfaces with high precision of roughness after grinding', In Manufacturing Technology. June 2012, vol. 12, pp. 66-70. ISSN 12132489.
[6] LAT'TNER, R., HOLESOVSKY, F., NOVAK, M., VRABEL, M. (2016). 'Grinding of Titanium Alloy Ti6Al4V with Silicon Carbide Grinding Wheel'. In Manufacturing Technology. 2016, vol. 16, no. 1, pp. 159-162. ISSN 12132489

[7] NOVAK, M., NAPRSTKOVA, N. (2015). 'Grinding of the alloy INCONEL 718 and final roughness of the surface and material share'. In Manufacturing Technology. December 2015, vol. 15, no. 6, pp. 1015-1023. ISSN 12132489.

[8] DENKENA, B., GROVE, T., LUCAS, H. (2016). 'Influences of grinding with Toric CBN grinding tools on surface and subsurface of 1.3344PM steel'. In Journal of Materials Processing Technology. March 2016, vol. 229, pp. 541-548, ISSN 0924-0136.

[9] LUKOVICS, I. (2006) 'HIGH-SPEED GRINDING OF TOOLS AND TOOLING'. A shortened version of habilitation work. Brno 2016. ISSN 1213-418X, ISBN 80-214-3305-1. [cit. 2017-07-20]. Available: http://www.vutium.vutbr.cz/tituly/pdf/ukazka/80-214-3305-1.pdf

[10] MaragingSteel MS1 Material data sheet, [cit. 2017-07-25]. Available: https://www.axisproto.com/pdf/MaragingSteel_MS1_Material_data_sheet_0707 en.pdf

[11] DIN X3NiCoMoTi18-9-5 standard specification. [cit. 2017-07-25]. Available: http://www.find-steel.com/steel-grades/ToolSteel/x3nicomoti18-9-5-2848.html 